\title{
Acute Mucociliary Clearance Response to Aerobic Exercise in Smokers
}

\author{
Ercy MC Ramos PhD, Luiz Carlos M Vanderlei PhD, Juliana T Ito MSc, Fabiano F Lima, \\ Fernanda MM Rodrigues MSc, Beatriz M Manzano PhD, Rômulo A Fernandes PhD, \\ Michel J Cecílio MD, Alessandra C Toledo-Arruda PhD, and Dionei Ramos PhD
}

\begin{abstract}
BACKGROUND: Mucociliary clearance is the main defense mechanism of the respiratory system, and it is influenced by several stimuli, including aerobic exercise and cigarette smoking. We evaluated the acute response of mucociliary clearance to aerobic exercise in smokers and nonsmokers compared with that found after acute smoking and smoking combined with exercise. Also, we investigated whether there was a correlation between mucociliary clearance and the autonomic nervous system under these conditions. METHODS: Twenty-one smokers were evaluated for mucociliary clearance by saccharin transit time (STT), and the response of the autonomic nervous system was evaluated by heart rate variability after aerobic exercise, after exercise followed by smoking, after acute smoking, and after rest. For comparison, 17 nonsmokers were also assessed during exercise. Repeated-measures analysis of variance with the Tukey test or the Friedman test followed by the Dunn test was used to evaluate the STT, autonomic response, and other variables to exercise and/or smoking in smokers. A paired $t$ test or Wilcoxon test was used to analyze responses to exercise in nonsmokers. Correlations were evaluated using Pearson or Spearman coefficients. RESULTS: The STT was reduced after exercise in both groups, with similar responses between them. Other stimuli also reduced the STT. The STT showed a negative correlation with sympathetic activity in smokers and a positive correlation with the parasympathetic system in nonsmokers. CONCLUSIONS: Although impaired in smokers, mucociliary clearance responded to the stimulus of exercise, as demonstrated by similar STTs compared with nonsmokers. This response was correlated with the autonomic nervous system in both groups. In smokers, mucociliary clearance also responded to the stimuli of smoking and exercise followed by smoking. Key words: aerobic exercise; airway; autonomic nervous system; mucociliary clearance; smoking; physical exercise. [Respir Care 2015;60(11):1575-1584. (C) 2015 Daedalus Enterprises]
\end{abstract}

\section{Introduction}

Continuous exposure to the chemical substances contained in cigarette smoke causes epithelial remodeling,

Dr EMC Ramos, Dr Vanderlei, Ms Ito, Mr Lima, Ms Rodrigues, and Dr D Ramos are affiliated with the Department of Physiotherapy, and Dr Fernandes is affiliated with the Department of Physical Education, Universidade Estadual Paulista (UNESP), Presidente Prudente, São Paulo, Brazil. Dr Manzano is affiliated with the Department of Pulmonology, Universidade Federal de São Paulo (UNIFESP)/Escola Paulista de Medicina (EPM), São Paulo, São Paulo, Brazil. Dr Cecílio is affiliated with the Department of Medicine, Universidade do Oeste Paulista (UNOESTE), Presidente Prudente, São Paulo, Brazil. Dr Toledo-Arruda is affiliated with the Department of Clinical Medicine, Faculdade de Medicina da Universidade de São Paulo (FMUSP), São Paulo, São Paulo, Brazil.

This study was supported by the Pró-Reitoria de Extensão Universitária (PROEX)/Universidade Estadual Paulista (UNESP), Fundação de Amparo with an increased number of goblet cells, hypertrophy of mucous cells, and the loss of ciliated cells. This leads to an increase in the production of mucus and a reduced ability to eliminate it, resulting in impaired mucociliary clearance ${ }^{1-3}$ compared with nonsmokers. ${ }^{4}$ However, a reduction

\footnotetext{
à Pesquisa do Estado de São Paulo (FAPESP) grants 2012/09932-0 and 2012/04699-6, and Conselho Nacional de Desenvolvimento Científico e Tecnológico (CNPq) grant 2012/484658. This study was registered in the Brazilian Clinical Trials Registry (CAAE: 04397312.8.0000.5402). The authors have disclosed no conflicts of interest.

Correspondence: Ercy MC Ramos PhD, Departamento de Fisioterapia, Universidade Estadual Paulista, Rua Roberto Simonsen, $n^{\circ} 305$, Presidente Prudente, São Paulo, CEP 19060-900, Brazil. E-mail: ercy@bol.com.br, ercy@fct.unesp.br.
}

DOI: $10.4187 /$ respcare.04093 
in mucociliary clearance time occurs in smokers immediately after smoking, and mucociliary clearance becomes similar to that found in nonsmokers. ${ }^{5}$ This seems to be mediated by activation of the sympathetic nervous system due to the release of catecholamines stemming from the activation of nicotinic receptors. ${ }^{6}$

The execution of aerobic physical activity can also enhance mucociliary clearance. A previous study found improved clearance of radioactive particles in nonsmokers after performing $30 \mathrm{~min}$ of aerobic exercise on a stationary bicycle, which is a stimulus that also increases sympathetic activity and the level of circulating catecholamines. ${ }^{8,9}$ However, it is not known whether mucociliary clearance in smokers responds to the stimulus of aerobic exercise with similar efficiency to that found in nonsmokers or whether this response differs from that of the stimulus of acute smoking or smoking combined with acute exercise. Moreover, it is not known whether mucociliary clearance is influenced by the autonomic nervous system under these conditions.

The aims of this study were to evaluate the acute response of mucociliary clearance to moderate aerobic exercise in smokers and nonsmokers and to compare this response with that found following acute smoking and smoking combined with exercise. An additional aim was to investigate the possible correlation between mucociliary clearance and the autonomic nervous system. The hypothesis is that aerobic exercise stimulates mucociliary clearance in smokers, contributing to the proper functioning of one of the main pulmonary defense mechanisms in such individuals, and that the stimuli of acute smoking and smoking combined with exercise also promote an increased mucociliary clearance response. Moreover, it is believed that the autonomic nervous system is associated with the mucociliary clearance response under these conditions.

\section{Methods}

A prospective, cross-sectional, randomized controlled trial was carried out with smokers and nonsmokers of both sexes $30-50$ y old. The inclusion criterion was normal lung function as determined by spirometry. The exclusion criteria were cerebrovascular, cardiac, orthopedic, metabolic, or rheumatic disease; hypertension; diabetes; alcoholism; or any adverse health condition that could interfere with exercise performance or autonomic modulation. Individuals who did not understand or did not cooperate with the procedures and research methods, those who did not attend the sessions, and those with recent respiratory infections were also excluded.

All volunteers received clarifications regarding the procedures and signed a statement of informed consent, agreeing to participate in the study. This study received ap-

\section{QUICK LOOK}

\section{Current knowledge}

Mucociliary clearance is the main defense mechanism of the respiratory system, and it is influenced by several stimuli, including aerobic exercise and cigarette smoking. Continuous exposure to the chemical substances contained in cigarette smoke causes epithelial remodeling, with an increased number of goblet cells, hypertrophy of mucous cells, and the loss of ciliated cells. This leads to an increase in the production of mucus and a reduced ability to eliminate it, resulting in impaired mucociliary clearance compared with nonsmokers.

\section{What this paper contributes to our knowledge}

Mucociliary clearance in smokers responded to the stimulus of moderate aerobic exercise similarly to that in nonsmokers. Changes in mucociliary clearance were also seen after acute smoking and after exercise followed by smoking, with a shorter clearance time in smokers, but with no significant differences among the evaluated stimuli. Correlations were found between mucociliary clearance and cardiac autonomic activity in both smokers and nonsmokers after the exercise stimulus.

proval from the human research ethics committee of the Universidade Estadual Paulista (study 18/2011).

\section{Study Protocols}

On the days of the protocol, subjects were instructed to eat a light meal $2 \mathrm{~h}$ before evaluation and to abstain from alcohol, caffeine, smoking, and vigorous physical activity for $12 \mathrm{~h}$ before evaluation. On the first day of the protocol, all subjects underwent an initial evaluation, which included an interview, exhaled carbon monoxide measurement, and spirometry. The following day, participants performed a progressive and exhausting treadmill test for the individual prescription of exercise intensity.

All evaluations were carried out in a room with controlled temperature $\left(22.35 \pm 0.29^{\circ} \mathrm{C}\right)$ and relative humidity $(54.50 \pm 1.97 \%)$. The smokers were initially placed at rest in a sitting position for $20 \mathrm{~min}$ and randomly assigned to the following protocols with a 48 -h interval between sessions: P1, 20 min of aerobic exercise on a treadmill, followed immediately by smoking 2 cigarettes while seated within $\sim 20 \mathrm{~min}$; P2, $20 \mathrm{~min}$ of aerobic exercise on a treadmill; P3, smoking 2 cigarettes while seated within 20 $\mathrm{min}$; and $\mathrm{P} 4$, at rest in a sitting position for $20 \mathrm{~min}$. Heart 


\section{Acute Mucociliary Clearance Response to Aerobic Exercise in Smokers}

rate variability, exhaled carbon monoxide, and mucociliary clearance by saccharin transit time (STT) test were evaluated after each protocol. Nonsmokers performed only protocols $\mathrm{P} 2$ and $\mathrm{P} 4$, the order of which was determined randomly.

\section{Initial Evaluation}

All subjects were interviewed to obtain information on personal data and medical history (surgery or nasal trauma, chronic respiratory disease, and infection in the previous weeks). Exhaled carbon monoxide was measured at the beginning of each protocol to determine abstinence from smoking ${ }^{10}$ in both groups. Smokers were also asked about their smoking history (years of smoking, no. of cigarettes/d) and were classified according to the intensity of daily tobacco consumption ${ }^{11}$ and the degree of nicotine dependence as assessed using the Fagerström test. ${ }^{12}$

\section{Lung Function, Exhaled Carbon Monoxide, and Carboxyhemoglobin}

Spirometry was performed following the guidelines of the American Thoracic Society and the European Respiratory Society ${ }^{13}$ using a portable spirometer (Spirobank 3.6, Medical International Research, Rome, Italy) and specific reference values for the Brazilian population. ${ }^{14}$ Exhaled carbon monoxide levels were used as biochemical markers to confirm self-reported abstinence from smoking. ${ }^{15}$ Exhaled carbon monoxide and carboxyhemoglobin were measured using a carbon monoxide analyzer (Micro CO meter, Cardinal Health, Dublin, Ohio). Subjects were instructed to take a deep breath, followed by $20 \mathrm{~s}$ of apnea. The mouthpiece of the device was then put into place, and subjects were instructed to perform slow exhalation. ${ }^{16}$

\section{Cardiopulmonary Exercise Test}

To determine maximum oxygen uptake $\left(\dot{\mathrm{V}}_{\mathrm{O}_{2}}\right)$ and prescription of aerobic exercise, subjects underwent cardiopulmonary exercise testing on a treadmill (Inbrasport ATL 2000, Inbrasport, Rio Grande do Sul, Brazil) at an initial velocity of $5.0 \mathrm{~km} / \mathrm{h}$, constant inclination (1\%), with increments in velocity $(0.5 \mathrm{~km} / \mathrm{h})$ every $2 \mathrm{~min}$. The test was performed to exhaustion. ${ }^{17}$ No subject experienced any clinical or electrocardiography events that prevented completion of the test. A cardiologist was present during the test, and the following variables were continuously monitored: heart rate (Polar S810i, Polar Ectro, Kempele, Finland), arterial blood oxygen saturation (BCI 3303 pulse oximeter, Portex-Smiths Medical, Dublin, Ohio), and ventilatory variables, which were obtained using a gas analyzer $\left(\mathrm{VO}_{2000}\right.$, Medical Graphics, Saint Paul, Minnesota). The gas analyzer was calibrated before each test following the manufacturer's specifications. Medium air flow was used on all tests, and gas samples were taken every $10 \mathrm{~s}$ (Aerograph software 4.3, AeroSport Inc., Ann Arbor, Michigan).

To determine blood lactate concentrations, blood samples $(25 \mu \mathrm{L})$ were collected from the earlobe during the initial rest and immediately after exhaustion. The samples were analyzed in a lactate analyzer (Model YSI 1500 SPORT, Yellow Springs, Ohio) using the electrochemical method. All participants were required to meet at least 2 of the 3 criteria for determining maximum $\dot{\mathrm{V}}_{\mathrm{O}_{2}}$ : (1) heart rate of $>90 \%$ of the maximum predicted for age $(220-$ age $)$, (2) respiratory quotient of $>1.10$, and (3) peak lactate levels of $>8 \mathrm{mM} \cdot{ }^{18}$ Maximum $\dot{\mathrm{V}}_{\mathrm{O}_{2}}$ was assumed to be the highest mean value in the last minute of the test. The ventilatory equivalent for carbon dioxide and end-tidal $\mathrm{CO}_{2}$ were plotted against time to determine the second ventilatory threshold, which was assumed to be the corresponding intensity to the increase in the ventilatory equivalent for carbon dioxide together with end-tidal $\mathrm{CO}_{2} \cdot{ }^{19-21}$

\section{Exercise Prescription}

The aerobic exercise session was prescribed based on the results of cardiopulmonary exercise testing. For moderate intensity, subjects performed $20 \mathrm{~min}$ of sustained effort on the treadmill at a speed corresponding to $90 \%$ of threshold $2\left(\sim 60-70 \%\right.$ of maximum $\left.\dot{\mathrm{V}}_{\mathrm{O}_{2}}\right)$. Before the exercise, subjects performed 2 min of warm-up at a mild intensity (half the individually prescribed speed).

\section{Nasal Mucociliary Clearance}

The STT is a measure of nasal mucociliary clearance that has been widely used in previous studies. ${ }^{5,22-24}$ The STT test is a noninvasive, valid, simple, and reproducible method to determine mucociliary clearance. ${ }^{25,26}$ Moreover, nasal mucociliary clearance correlates well with tracheobronchial clearance, ${ }^{26,27}$ which eliminates the need for invasive procedures. ${ }^{28}$

Subjects were seated with their head extended at $10^{\circ}$, and $250 \mu \mathrm{g}$ of granulated sodium saccharin was deposited under visual control $\sim 2 \mathrm{~cm}$ inside the right nostril. The time from saccharin placement to the first perception of a sweet taste in the mouth was recorded in minutes with a digital timer (Model 1046, Kenko, Ciudad del Este, Paraguay). Subjects were instructed not to breathe deeply, talk, cough, sneeze, or sniff during the test. Moreover, subjects were instructed not to use medications, such as anesthetics, analgesics, anticonvulsants, antidepressants, or tranquilizers, at least $12 \mathrm{~h}$ before the test. 


\section{Autonomic Nervous System Modulation}

To evaluate autonomic modulation, an elastic catchment strap was placed on the subject's chest at the height of the xiphoid process, and a heart rate monitor was placed on the wrist (Polar Electro). This equipment has been previously validated for capturing beat-to-beat heart rate and for calculating the different heart rate variability indexes. ${ }^{29,30}$ Heart rate was recorded individually with subjects at rest in a silent sitting position.

For analysis of heart rate variability indexes with each protocol, 256 consecutive RR intervals were selected from the most stable portion of the time corresponding to the STT evaluation, that is, 128 heart beats before and 128 after the subjects reported tasting saccharin. The reading was submitted to digital filtering using Polar Precision Performance SW 4.01.029 (Polar Electro) with manual filtering to eliminate ectopic premature beats and artifacts. Only series with $>95 \%$ sinus rhythm were considered. Analysis was performed with the Kubios program (Biosignal and Medical Image Analysis Group, Department of Physics, University of Kuopio, Kuopio, Finland). ${ }^{31}$

The following indexes in the time domain were analyzed: mean interval between adjacent normal heart beats (RR interval), the square root of the sum of successive differences between RR intervals (RMSSD, expressed in $\mathrm{ms}$ ), and the SD of all normal RR intervals (SDNN, expressed in $\mathrm{ms}) .^{32,33}$ The following indexes of the frequency domain were analyzed: spectral components of low (LF, $0.04-0.15 \mathrm{~Hz}$ ) and high (HF, $0.15-0.40 \mathrm{~Hz}$ ) frequency (expressed in absolute values $\left[\mathrm{ms}^{2}\right]$ and normalized units) and the LF/HF ratio. Spectral analysis was performed using the fast Fourier transform algorithm. ${ }^{34}$

Quantitative analysis of the Poincaré plot was also used for heart rate variability analysis. This plot is a diagram in which each RR interval is plotted as a function of the previous RR interval. Quantitative analysis was performed by adjusting the ellipse of the figure formed by the attractor, from which the following indexes were calculated: SD of instantaneous beat-to-beat variability (SD1), SD of longterm variability (SD2), and the SD1/SD2 ratio. ${ }^{35,36}$

\section{Statistical Analysis}

SPSS 13.0 (SPSS, Chicago, Illinois) was used for data analysis. The Shapiro-Wilk test was used to determine the distribution of the data. Parametric data were expressed as the mean $\pm \mathrm{SD}$, and nonparametric data were expressed as the median (interquartile range). Depending on the distribution of the data, either the unpaired $t$ test or the MannWhitney test was used for the intergroup comparisons (smokers vs nonsmokers).

In the intragroup analysis of the smokers (P1, P2, P3, and P4), the Mauchly test was used to determine the sphe-

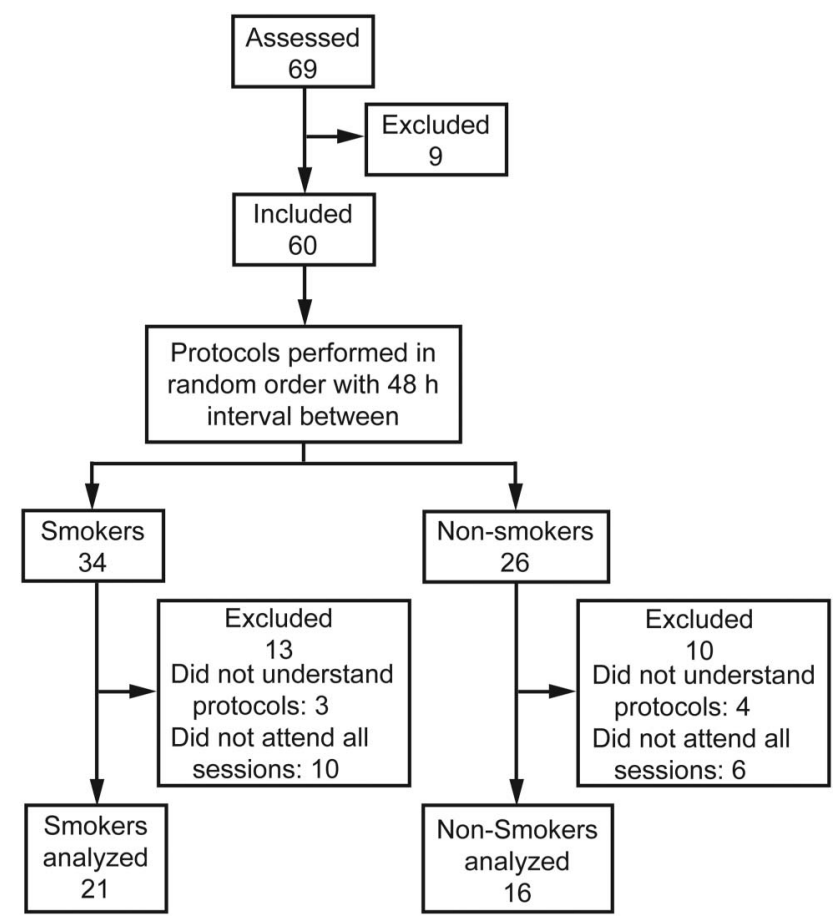

Fig. 1. Flow chart.

ricity of the data. When the assumption of sphericity was met, repeated-measures analysis of variance followed by the Tukey post hoc test was used. When this assumption was not met, the Friedman test followed by the Dunn post hoc test was used. In the intragroup analysis of the nonsmokers ( $\mathrm{P} 2$ and $\mathrm{P} 4)$, either the paired $t$ test or the Wilcoxon test was used depending on the distribution of the data. Correlations were evaluated using either Pearson or Spearman coefficients depending on the distribution of the data. The level of significance was set to $5 \%(P<.05)$.

\section{Results}

Sixty-nine subjects were recruited for the study: 44 in the smoking group and 25 in the nonsmoking group. However, following application of the eligibility criterion, the final sample included 21 smokers and 16 nonsmokers (Fig. 1).

\section{Characteristics of Subjects, Pulmonary Function, and Maximum $\dot{\mathbf{V}}_{\mathbf{O}_{2}}$}

Table 1 displays the anthropometric data, smoking history, spirometric values, and maximum $\dot{\mathrm{V}}_{\mathrm{O}_{2}}$ of the smokers and nonsmokers. The groups were matched for age and body mass index. Most smokers reported moderate tobacco consumption (53.8\%), and a large portion had highto-very-high nicotine dependence (44.4\%). Smokers had a 


\section{Acute Mucociliary Clearance Response to Aerobic Exercise in Smokers}

Table 1. Characterization of Smokers and Nonsmokers According to Age, Body Mass Index, Smoking History, Spirometry, and Maximum $\dot{\mathrm{V}}_{\mathrm{O}_{2}}$

\begin{tabular}{|c|c|c|c|}
\hline Variable & Smokers $(n=21)$ & Nonsmokers $(n=16)$ & $P$ \\
\hline Age, mean \pm SD y & $41.2 \pm 6.0$ & $40.2 \pm 6.1$ & .60 \\
\hline $\mathrm{BMI}$, mean $\pm \mathrm{SD} \mathrm{kg} / \mathrm{m}^{2}$ & $24.5 \pm 3.5$ & $26.6 \pm 5.5$ & .12 \\
\hline \multicolumn{4}{|l|}{ Smoking history } \\
\hline Years of smoking, mean $\pm \mathrm{SD}$ & $22.6 \pm 8.8$ & NA & NA \\
\hline No. of cigarettes/d, mean $\pm \mathrm{SD}$ & $19.4 \pm 10.7$ & NA & NA \\
\hline Light smokers, $\%$ & 30.8 & NA & NA \\
\hline Moderate smokers, $\%$ & 53.8 & NA & NA \\
\hline Heavy smokers, $\%$ & 15.4 & NA & NA \\
\hline Pack-years, mean \pm SD & $20.4 \pm 12.4$ & NA & NA \\
\hline Fagerström score, mean $\pm \mathrm{SD}$ & $5.7 \pm 2.2$ & NA & NA \\
\hline Very low to low, \% & 26 & NA & NA \\
\hline Moderate, $\%$ & 29.6 & NA & NA \\
\hline High to very high, $\%$ & 44.4 & NA & NA \\
\hline \multicolumn{4}{|l|}{ Spirometry } \\
\hline $\mathrm{FEV}_{1}$, mean $\pm \mathrm{SD} \%$ predicted & $91.2 \pm 14.7$ & $101.5 \pm 11.6^{*}$ & .02 \\
\hline $\mathrm{FVC}$, mean $\pm \mathrm{SD} \%$ predicted & $97.7 \pm 11.4$ & $103.6 \pm 12.3$ & .12 \\
\hline $\mathrm{FEV}_{1} / \mathrm{FVC}$, mean $\pm \mathrm{SD}$ & $0.78 \pm 0.09$ & $0.82 \pm 0.06$ & .12 \\
\hline Maximum $\dot{\mathrm{V}}_{\mathrm{O}_{2}}$, mean $\pm \mathrm{SD} \mathrm{mL} / \mathrm{kg} / \mathrm{min}$ & $21.5 \pm 8.8$ & $30.2 \pm 12.2^{*}$ & .038 \\
\hline \multicolumn{4}{|l|}{$\begin{array}{l}\text { * Statistically significant difference compared with smokers. } \\
\dot{\mathrm{V}}_{\mathrm{O}_{2}}=\text { oxygen uptake } \\
\text { BMI = body mass index } \\
\mathrm{NA}=\text { not applicable }\end{array}$} \\
\hline
\end{tabular}

Table 2. STT, Exhaled Carbon Monoxide, and Carboxyhemoglobin After Each Protocol: P1, P2, P3, and P4 for Smokers and P2 and P4 for Nonsmokers

\begin{tabular}{|c|c|c|c|c|c|c|}
\hline \multirow{2}{*}{ Variable } & \multicolumn{4}{|c|}{ Smokers } & \multicolumn{2}{|c|}{ Nonsmokers } \\
\hline & $\mathrm{P} 1(n=21)$ & $\mathrm{P} 2(n=21)$ & $\mathrm{P} 3(n=21)$ & $\mathrm{P} 4(n=21)$ & $\mathrm{P} 2(n=16)$ & $\mathrm{P} 4(n=16)$ \\
\hline STT & $8.1(6.9-12.8)^{*}$ & $6.0(4.9-8.3)^{*}$ & $10.5(6.7-13.0)^{*}$ & $12.6(8.9-18.7)$ & $6.8(4.7-9.4) \dagger$ & $9.9(7.2-15.7) \ddagger$ \\
\hline Exhaled carbon monoxide, ppm & $13.5(9.7-22.0)$ & $9.0(7.0-14.0) \S$ & $18.0(10.0-29.0)$ & $10.0(6.0-16.0) \S$ & $2.0(0.5-3.0) \|$ & $2.0(1.2-3.0) \ddagger$ \\
\hline Carboxyhemoglobin, $\%$ & $2.1(1.5-3.5)$ & $1.4(1.0-2.2) \S$ & $3.0(1.7-5.2)$ & $1.7(0.9-2.5) \S$ & $0.3(0.1-0.5) \|$ & $0.3(0.2-0.5) \ddagger$ \\
\hline \multicolumn{7}{|c|}{$\begin{array}{l}\text { Data are expressed as the median (interquartile range). } \\
* P<.001 \text { compared with at rest (P4) in the smoking group. } \\
\dagger P<.040 \text { compared with } \mathrm{P} 4 \text { in the nonsmoking group. } \\
\ddagger P<.037 \text { compared with } \mathrm{P} 4 \text { in the smoking group. } \\
\S P=.001 \text { compared with smoking ( } \mathrm{P} 3) \text { in the smoking group. } \\
\| P<.001 \text { compared with aerobic exercise (P2) in the smoking group. } \\
\mathrm{P} 1=\text { aerobic exercise followed by smoking } \\
\mathrm{STT}=\text { saccharin transit time }\end{array}$} \\
\hline
\end{tabular}

lower percent-of-predicted $\mathrm{FEV}_{1}$, but with no indication of altered lung function. Smokers also had a lower maximum $\dot{\mathrm{V}}_{\mathrm{O}_{2}}$ compared with nonsmokers.

\section{STT and Exhaled Carbon Monoxide of Smokers and Nonsmokers in Each Protocol}

Table 2 displays the STT and exhaled carbon monoxide data during the different protocols in both groups. At rest (P4), the STT, exhaled carbon monoxide, and carboxyhemoglobin were significantly higher in smokers compared with nonsmokers. However, after aerobic exercise (P2), the STT was reduced significantly and was similar in both groups.

In intragroup analysis of the smokers, the STT was shorter after all stimuli (P1, P2, and P3) compared with the resting condition $(\mathrm{P} 4)$, but no significant differences were found between protocols. After acute smoking (P3), exhaled carbon monoxide and carboxyhemoglobin were significantly higher compared with $\mathrm{P} 2$ and $\mathrm{P} 4$ and similar to the values found after the exercise protocol followed by smoking (P1). Among the nonsmokers, a significant re- 


\section{Acute Mucociliary Clearance Response to Aerobic Exercise in Smokers}

Table 3. Heart Rate Variability Indexes Evaluated in Each Experimental Protocol: P1, P2, P3, and P4 for Smokers and P2 and P4 for Nonsmokers

\begin{tabular}{|c|c|c|c|c|c|c|}
\hline \multirow{2}{*}{ Variable } & \multicolumn{4}{|c|}{ Smokers } & \multicolumn{2}{|c|}{ Nonsmokers } \\
\hline & $\mathrm{P} 1(n=21)$ & $\mathrm{P} 2(n=21)$ & $\mathrm{P} 3(n=21)$ & $\mathrm{P} 4(n=21)$ & $\mathrm{P} 2(n=16)$ & $\mathrm{P} 4(n=16)$ \\
\hline SDNN & $26.0(20.5-38.0)^{*}$ & $29.0(22.0-43.0)^{*}$ & $37.0(25.7-43.7)^{*}$ & $41.0(31.0-51.0)$ & $24.0(18.5-33.0) \dagger$ & $35.5(27.7-59.0)$ \\
\hline RMSSD & $16.0(11.1-285)^{*}$ & $14.2(11.3-31.5)^{*}$ & $29.9(16.0-41.7)$ & $29.1(18.0-39.4)$ & $11.5(8.8-20.4) \dagger$ & $20.2(16.4-37.8)$ \\
\hline $\mathrm{SD} 1, \mathrm{~ms}$ & $11.5(8.0-20.5) \ddagger$ & $12.9(9.5-23.0)$ & $21.4(11.6-29.8)$ & $20.8(12.9-28.5)$ & $8.3(6.4-14.7) \dagger \S$ & $14.5(11.8-27.0)$ \\
\hline $\mathrm{SD} 2, \mathrm{~ms}$ & $45.7(35.3-58.6)^{*}$ & $44.7(34.8-63.9)^{*}$ & $52.5(40.5-61.2)^{*}$ & $67.3(50.9-74.8)$ & $37.1(31.7-53.8) \dagger$ & $56.9(44.7-84.7)$ \\
\hline $\mathrm{LF}, \mathrm{ms}^{2}$ & $31.0(15.0-70.2)^{*}$ & $35.0(16.0-93.5)^{*}$ & $73.0(25.0-99.5)$ & $108.0(57.0-282.0)$ & $17.0(12.5-61.0) \dagger$ & $58.5(34.2-246.5)$ \\
\hline $\mathrm{HF}, \mathrm{ms}^{2}$ & $10.5(5.0-44.7) \ddagger$ & $13.0(8.0-82.0)$ & $49.0(10.5-92.0)$ & $61.0(18.0-121.0)$ & $4.0(2.5-17.0) \dagger \S$ & $20.5(12.5-71.2)$ \\
\hline LF, normalized unit & $73.0(62.2-81.3)$ & $68.5(51.7-78.3)$ & 67.7 (48.9-76.5) & $73.8(53.3-79.9)$ & $84.9(66.4-89.8) \S$ & $71.5(60.9-83.2)$ \\
\hline HF, normalized unit & $26.9(18.6-37.7)$ & $31.5(21.6-48.3)$ & $32.3(23.5-50.0)$ & $26.2(20.1-46.7)$ & $15.1(10.1-33.6) \S$ & $28.5(16.7-39.0)$ \\
\hline $\mathrm{LF} / \mathrm{HF}$ & $2.7(1.6-4.4)$ & $2.1(1.1-3.6)$ & $2.1(0.9-3.2)$ & $2.8(1.1-3.9)$ & $5.6(1.9-8.9) \dagger \S$ & $2.5(1.5-4.9)$ \\
\hline
\end{tabular}

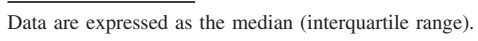

$* P<.001$ compared with $\mathrm{P} 4$ in the smoking group.

$\dagger P<.036$ compared with $\mathrm{P} 4$ in the nonsmoking group.

$\ddagger P<.004$ compared with $\mathrm{P} 4$ in the smoking group.

$\S P<.02$ compared with $\mathrm{P} 2$ in the smoking group.

$\mathrm{P} 1=$ aerobic exercise followed by smoking

$\mathrm{P} 2=$ aerobic exercise

$\mathrm{P} 3=$ smoking

$\mathrm{P} 4=$ at rest

$\mathrm{SDNN}=\mathrm{SD}$ of all normal RR intervals

RMSSD $=$ square root of sum of successive differences between normal adjacent RR intervals

SD1 $=$ SD of instantaneous beat-to-beat variability

$\mathrm{SD} 2=\mathrm{SD}$ of long-term continuous RR intervals

$\mathrm{LF}=$ low frequency

$\mathrm{HF}=$ high frequency

duction was found in the STT after P2, whereas exhaled carbon monoxide and carboxyhemoglobin remained unaltered.

\section{Heart Rate Variability Indexes of Smokers and Nonsmokers in Each Protocol}

Table 3 displays the heart rate variability indexes during the different protocols in both groups. At rest (P4), heart rate variability indexes did not differ significantly between groups. After the exercise stimulus (P2), $\mathrm{SD} 1, \mathrm{HF}\left(\mathrm{ms}^{2}\right)$, and HF (normalized units) were significantly lower in the nonsmokers compared with the smokers, whereas LF (normalized units) and the LF/HF ratio were higher in the nonsmokers compared with the smokers.

In intragroup analysis of the smokers, the SDNN, RMSSD, SD1, SD2, LF $\left(\mathrm{ms}^{2}\right)$, and HF $\left(\mathrm{ms}^{2}\right)$ indexes decreased significantly after exercise plus smoking (P1) compared with the resting condition (P4). The SDNN, RMSSD, $\mathrm{SD} 2$, and $\mathrm{LF}\left(\mathrm{ms}^{2}\right)$ indexes also decreased after isolated exercise (P2). The SDNN and SD2 indexes were lower after isolated smoking (P3) compared with P4. In nonsmokers, all heart rate variability indexes, except LF (normalized units) and HF (normalized units), changed significantly after P2.
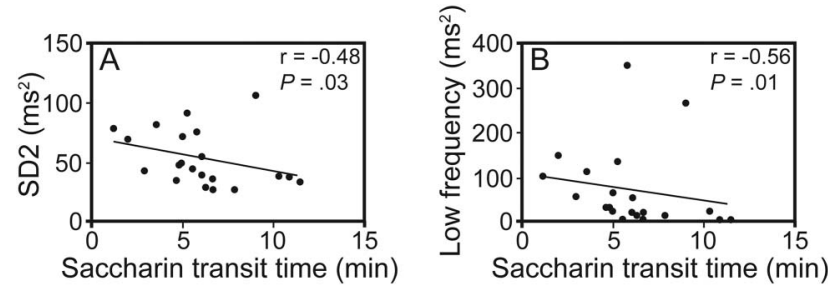

Fig. 2. Correlation between saccharin transit time and heart rate variability indexes in smokers. A: SD of long-term continuous $R R$ intervals (SD2). B: low frequency (LF, expressed in $\mathrm{ms}^{2}$ ).

\section{Correlations Between STT and Heart Rate Variability Indexes in Smokers and Nonsmokers}

The STT demonstrated a moderate negative correlation with the SD2 and LF $\left(\mathrm{ms}^{2}\right)$ indexes in smokers (Fig. 2) and a moderate positive correlation with the RMSSD, SD1, and $\mathrm{HF}\left(\mathrm{ms}^{2}\right)$ indexes in nonsmokers (Fig. 3).

\section{Discussion}

Acute moderate aerobic exercise increased mucociliary clearance in both smokers and nonsmokers. Indeed, both groups exhibited a similar response, and smokers showed mucociliary dysfunction at rest. Moreover, the combination of aerobic exercise and acute smoking also enhanced mucociliary clearance in the smokers, with no significant 

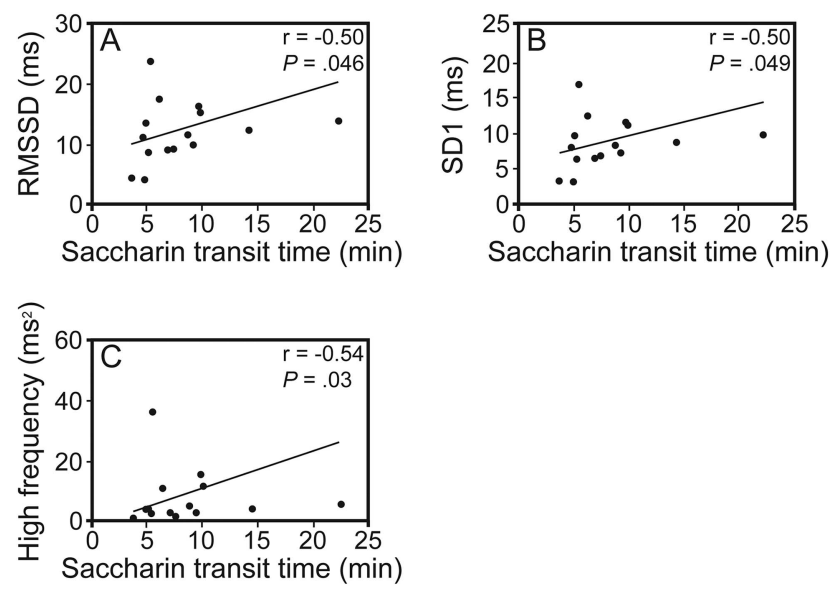

Fig. 3. Correlation between saccharin transit time and heart rate variability indexes in nonsmokers. A: Square root of the sum of successive differences between RR intervals (RMSSD). B: SD of instantaneous beat-to-beat variability (SD1). C: high frequency.

difference between the stimuli. The mucociliary clearance response to aerobic exercise was influenced by cardiac autonomic activity in both smokers and nonsmokers. The smokers had a lower percent-of-predicted $\mathrm{FEV}_{1}$, which demonstrates the harmful effect of smoking on lung function, although lung function was within the normal range ${ }^{37,38}$ in the smokers in this study because this was the inclusion criterion. Moreover, this group had lower maximum exercise capacity as reflected by the maximum $\dot{\mathrm{V}}_{\mathrm{O}_{2}}$ compared with nonsmokers. This finding is in agreement with data in previous studies ${ }^{39,40}$ reporting that smokers had reduced exercise capacity compared with nonsmokers.

\section{Mucociliary Clearance and Exhaled Carbon Monoxide Responses}

After moderate aerobic exercise, mucociliary clearance in the smokers was similar to that in the nonsmokers exposed to the same stimulus. Although slower than the mucociliary clearance in the nonsmokers at rest, mucociliary clearance in this group responded acutely to moderate exercise. This finding lends support to the hypothesis that the exercise stimulus leads to beneficial responses, even in smokers who already exhibit impairment with regard to this important defense mechanism.

The mechanism by which exercise improves mucociliary clearance is related to both sympathetic and parasympathetic stimulation. Increased ventilation stimulates upper-airway receptors. This results in increased vagal activity, which in turn accelerates mucociliary clearance due to the increase in mucus secretion. Moreover, physical exercise leads to high levels of plasma catecholamines (epinephrine and norepinephrine), which stimulate sympathetic activity and consequently accelerate ciliary beat frequency. $7,41,42$
A shorter mucociliary clearance time was also found in nonsmokers who performed aerobic exercise. This finding is in agreement with data described in a previous study, ${ }^{7}$ which reported acceleration of mucociliary clearance after aerobic exercise in healthy subjects as demonstrated by analysis of radiolabeled particles. However, Olséni et al ${ }^{43}$ found that moderate exercise did not improve mucociliary clearance in subjects with bronchial hypersecretion. This suggests that the mucociliary clearance response to exercise is influenced by the properties and amount of mucus. The acute responses of this mechanism following moderate exercise in both smokers and nonsmokers in our study may be related to the fact that no subject had hypersecretion in the upper airways, as confirmed by the questionnaire addressing any respiratory infections that preceded each experimental protocol.

The stimulus of acute smoking also reduced the STT, but with less intensity compared with moderate aerobic exercise, although no significant difference was found between these 2 stimuli. This acute change in mucociliary clearance was also reported by Proença et al, ${ }^{5}$ who found that the STT in smokers immediately after smoking equaled that in nonsmokers at baseline. Such behavior may be explained by the acceleration in ciliary beat frequency due to the stimulus of inflammatory mediators generated by an acute response of the respiratory epithelium to the offending agent (cigarette smoke) ${ }^{44}$ and the stimulation of sympathetic activity caused by nicotine, which activates general metabolism. ${ }^{45}$ However, the acute effect of smoking remains only until the nicotine is metabolized, after which mucociliary clearance slows again, reflecting the chronic effect of smoking. ${ }^{5}$

Regarding the effect of the combination of both aerobic exercise and smoking on mucociliary clearance, the STT was also shorter compared with the resting condition. The combined stimuli were expected to lead to a more enhanced mucociliary response. However, no significant differences were found among the different stimuli. Nonetheless, despite the lack of statistical significance, aerobic exercise alone led to greater mucociliary clearance compared with the combined stimuli. One hypothesis for this response is the fact that smoking occurred immediately following exercise, which may have reduced the effect of exercise. Thus, as mucociliary clearance was evaluated only after smoking in the $\mathrm{P} 1$ protocol, the stress caused by exercise, such as hyperventilation and sympathetic stimulation, may have been attenuated after the subjects sat down and began smoking. The different mechanisms by which exercise and smoking modify mucociliary clearance may have exerted an influence on this response.

The measurement of carbon monoxide levels is a noninvasive method considered to be the accepted standard for detecting very recent smoking. ${ }^{15,46,47}$ The increased levels in smokers confirmed this, as carbon monoxide lev- 


\section{Acute Mucociliary Clearance Response to Aerobic Exercise in Smokers}

els were more pronounced after acute smoking than after smoking following aerobic exercise. This may be explained by the effect of exercise, which increases breathing frequency and consequently increases elimination of carbon monoxide. ${ }^{48}$ It is therefore assumed that exercise provided the initial elimination of this gas to levels below those found at rest.

\section{Cardiac Autonomic Modulation Response}

At baseline, smokers and nonsmokers had similar cardiac autonomic modulation, which differs from findings described in previous studies reporting autonomic nervous system dysfunction in smokers. ${ }^{49-51}$ The profile of the our sample may have influenced this finding because smoking history exerts an influence on this system. ${ }^{52}$ The smoking group consisted of individuals with different intensities of smoking consumption, which may have masked the result, as a light smoker may not exhibit autonomic changes, and influenced the outcome, as heavy smokers may have autonomic dysfunction.

Exercise causes major changes in the functioning of the cardiovascular system and its mechanisms of autonomic adjustment. ${ }^{53,54}$ In this study, a reduction in heart rate variability indexes occurred following moderate aerobic exercise, characterized by the predominance of sympathetic over parasympathetic activity in both groups, with a more pronounced response in nonsmokers. Alonso et $\mathrm{al}^{53}$ analyzed heart rate variability in adult subjects submitted to an exercise test on a stationary bicycle and also found a reduction in heart rate variability. This decrease is suggested to be largely dependent on vagal withdrawal.

Acute smoking also affected cardiac autonomic modulation, as reflected by the significant reduction in the SDNN and SD2 indexes, which represent overall variability. This is in agreement with findings described in previous studies in which changes in heart rate variability indexes were found in the time and frequency domains after cigarette smoking. ${ }^{55}$ Acute changes in cardiac autonomic control induced by smoking are mostly attributed to nicotine, which stimulates the release of catecholamines (norepinephrine and epinephrine) through activation of nicotinic receptors located on sympathetic nerve endings and the adrenal glands, causing widespread adrenergic stimulation at the peripheral level. ${ }^{56}$

The combination of both stimuli led to a significant reduction in all heart rate variability indexes, except LF (normalized units), HF (normalized units), and the LF/HF ratio. The combined stimuli of exercise and smoking led to a further reduction in SD1 and $\mathrm{HF}\left(\mathrm{ms}^{2}\right)$ indexes, which reflect vagal activity, whereas these variables did not respond to the stimulus of exercise alone. As mentioned above, ${ }^{56}$ the effect of nicotine on the autonomic nervous system leads to sympathetic activation mediated by the increase in plasma catecholamines, but is also associated with a reduction in vagal tone, ${ }^{57}$ which seems to be related to the effect of smoking on sinus node automaticity. In light of this, the acute effect of smoking added to exercise led to a reduction in vagal activity, which is also reflected by these heart rate variability indexes.

\section{Correlations Between Mucociliary Clearance and Heart Rate Variability Indexes}

Proper mucociliary clearance depends on the amount of mucus, its rheological properties, intact ciliary structure and activity, and the perfect interaction among these components. Neurohormones and neurotransmitters associated with the autonomic nervous system also exert a significant influence on mucociliary clearance because cholinergic and adrenergic agents stimulate the mucociliary activity or ciliary beat frequency. ${ }^{41,58}$ Thus, the association between mucociliary clearance and the autonomic nervous system was also investigated in this study with heart rate variability indexes, and significant correlations were found in both groups when submitted to aerobic exercise.

A moderate negative correlation was found between the STT and both SD2 and LF $\left(\mathrm{ms}^{2}\right)$ in the group of smokers. Thus, a greater sympathetic response, as reflected by LF $\left(\mathrm{ms}^{2}\right)$, denotes better mucociliary transportability. This finding confirms the influence of the autonomic nervous system, specifically sympathetic activity, on the increase in mucociliary clearance. The SD2 index represents both sympathetic and parasympathetic activities, but does not allow one to distinguish whether a change is due to increased sympathetic tone or the withdrawal of vagal tone. ${ }^{59}$ Because this index refers to the response to exercise, it is suggested to be influenced mainly by sympathetic activity.

A moderate positive correlation was found between the STT in nonsmokers and RMSSD, SD1, and HF $\left(\mathrm{ms}^{2}\right)$, indicating that lower vagal activity is related to a shorter STT (ie, enhanced mucociliary clearance). This explains the effect promoted by exercise on the autonomic nervous system, as demonstrated by the increase in sympathetic activity and reduction in vagal activity, which affect mucociliary clearance, improving this mechanism after exposure to aerobic exercise.

The association between cardiac autonomic activity and mucociliary clearance was found only during an acute response to one form of stimulus. Thus, further studies are needed to evaluate the relationship between systems in response to different stimuli to clarify this issue.

One limiting factor of this study concerns the protocol used to evaluate the combined effect of aerobic exercise and smoking on mucociliary clearance and cardiac autonomic control. The way this protocol was implemented may have attenuated the effect of one of the stimuli and therefore may not have reflected the sum of both. Another 


\section{Acute Mucociliary Clearance Response to Aerobic Exercise in Smokers}

limiting factor is the variation in the characteristics of the smokers, which may have led to the lack of significant differences between groups regarding heart rate variability indexes. Categorization according to smoking conditions can make future samples homogeneous and therefore contribute to different findings. One should also bear in mind that the assessment of cardiac autonomic modulation was performed in the time interval in which mucociliary clearance was evaluated to investigate the relationship between the autonomic nervous system and mucociliary clearance. Therefore, the moment used to evaluate the autonomic nervous system in the 4 protocols varied among subjects, which may have influenced the response of the heart rate variability indexes.

Because the STT is a measure used to evaluate the interaction between cilia and mucus components, it is also important to investigate the effect of exercise on each component through methods that assess mucus and cilia separately to determine whether either one has a greater influence on mucociliary clearance. Moreover, it is necessary to evaluate this response in subjects with different clinical respiratory conditions.

\section{Conclusions}

Based on our findings, mucociliary clearance in smokers responded to the stimulus of moderate aerobic exercise similarly to that in nonsmokers. Furthermore, this mechanism also responded to acute smoking and to exercise followed by smoking, with a shorter clearance time in smokers, but with no significant differences among the evaluated stimuli. Finally, correlations were found between mucociliary clearance and cardiac autonomic activity in both smokers and nonsmokers after the exercise stimulus.

\section{REFERENCES}

1. Koczulla AR, Noeske S, Herr C, Jörres RA, Römmelt H, Vogelmeier $\mathrm{C}$, Bals R. Acute and chronic effects of smoking on inflammation markers in exhaled breath condensate in current smokers. Respiration 2010;79(1):61-67.

2. Pagliuca G, Rosato C, Martellucci S, de Vincentiis M, Greco A, Fusconi M, et al. Cytologic and functional alterations of nasal mucosa in smokers: temporary or permanent damage? Otolaryngol Head Neck Surg 2015;152(4):740-745

3. Schamberger AC, Staab-Weijnitz CA, Mise-Racek N, Eickelberg O. Cigarette smoke alters primary human bronchial epithelial cell differentiation at the air-liquid interface. Sci Rep 2015;5:8163.

4. Cohen NA, Zhang S, Sharp DB, Tamashiro E, Chen B, Sorscher EJ, Woodworth BA. Cigarette smoke condensate inhibits transepithelial chloride transport and ciliary beat frequency. Laryngoscope 2009; 119(11):2269-2274

5. Proença M, Fagundes Xavier R, Ramos D, Cavalheri V, Pitta F, Ramos EMC. Immediate and short term effects of smoking on nasal mucociliary clearance in smokers. Rev Port Pneumol 2011;17(4): 172-176.
6. Teixeira L, Ritti-Dias RM, Tinucci T, Mion Júnior D, Forjaz CL. Post-concurrent exercise hemodynamics and cardiac autonomic modulation. Eur J Appl Physiol 2011;111(9):2069-2078.

7. Wolff RK, Dolovich MB, Obminski G, Newhouse MT. Effects of exercise and eucapnic hyperventilation on bronchial clearance in man. J Appl Physiol 1977;43(1):46-50.

8. Leopold PL, O'Mahony MJ, Lian XJ, Tilley AE, Harvey BG, Cristal RG. Smoking is associated with shortened airway cilia. PLoS ONE 2009;16;4(12):e8157.

9. Droguett VS, Santos Ada C, de Medeiros CE, Marques DP, do Nascimento LS, Brasileiro-Santos Mdo S. Cardiac autonomic modulation in healthy elderly after different intensities of dynamic exercise. Clin Interv Aging 2015;10:203-208.

10. Connor Gorber S, Schofield-Hurwitz S, Hardt J, Levasseur G, Tremblay M. The accuracy of self-reported smoking: a systematic review of the relationship between self-reported and cotinine-assessed smoking status. Nicotine Tob Res 2009;11(1):12-24.

11. Trosclair A, Dube SR. Smoking among adults reporting lifetime depression, anxiety, anxiety with depression, and major depressive episode, United States, 2005-2006. Addict Behav 2010;35(5):438443.

12. Meneses-Gaya IC, Zuardi AW, Loureiro SR, Crippa JAS. Psychometric properties of the Fagerström test for nicotine dependence. J Bras Pneumol 2009;35(1):73-82.

13. Miller MR, Hankinson J, Brusasco V, Burgos F, Casaburi R, Coates A, et al. Standardization of spirometry. Eur Respir J 2005;26(2):319338.

14. Duarte AA, Pereira CAC, Rodrigues SC. Validation of new Brazilian predicted values for forced spirometry in Caucasians and comparison with predicted values obtained using other reference equations. J Bras Pneumol 2007;33(5):527-535.

15. Middleton ET, Morice AH. Breath carbon monoxide as an indication of smoking habit. Chest 2000;117(3):758-763.

16. Jarvis MJ, Belcher M, Vesey C, Hutchison DC. Low cost carbon monoxide monitors in smoking assessment. Thorax 1986;41(11): 886-887.

17. Bentley DJ, Newell J, Bishop D. Incremental exercise test design and analysis: implications for performance diagnostics in endurance athletes. Sports Med 2007;37(7):575-586.

18. Midgley AW, Bentley DJ, Luttikholt H, McNaughton LR, Millet GP. Challenging a dogma of exercise physiology: does an incremental exercise test for valid $\mathrm{VO}_{2 \max }$ determination really need to last between 8 and 12 minutes? Sports Med 2008;38(6):441-447.

19. Esteve-Lanao J, San Juan AF, Earnest CP, Foster C, Lucia A. How do endurance runners actually train? Relationship with competition performance. Med Sci Sports Exerc 2005;37(3):496-504

20. Esteve-Lanao J, Foster C, Seiler S, Lucia A. Impact of training intensity distribution on performance in endurance athletes. J Strength Cond Res 2007;21(3):943-949.

21. Meyer T, Lucía A, Earnest CP, Kindermann W. A conceptual framework for performance diagnosis and training prescription from submaximal gas exchange parameters-theory and application. Int J Sports Med 2005;26(Suppl 1):S38-S48.

22. Salah B, Dinh Xuan AT, Fouilladieu JL, Lockhart A, Regnard J. Nasal mucociliary transport in healthy subjects is slower when breathing dry air. Eur Respir J 1988;1(9):852-855.

23. Ito JT, Ramos D, Lima FF, Rodrigues FM, Gomes PR, Moreira GL, Macchione M, Toledo AC, Ramos EMC. Nasal mucociliary clearance in subjects with COPD after smoking cessation. Respir Care 2015;60(3):399-405

24. Ramos EMC, De Toledo AC, Xavier RF, Fosco LC, Vieira RP, Ramos D, Jardim JR. Reversibility of impaired nasal mucociliary clearance in smokers following a smoking cessation programme. Respirology 2011;16(5):849-855. 


\section{Acute Mucociliary Clearance Response to Aerobic Exercise in Smokers}

25. Stanley P, MacWilliam L, Greenstone M, Mackay I, Cole P. Efficacy of saccharin test for screening to detect abnormal mucociliary clearance. Br J Dis Chest 1984;78(1):62-65.

26. Plaza Valía P, Carrión Valero F, Marín Pardo J, Bautista Rentero D, González Monte C. Saccharin test for the study of mucociliary clearance: reference values for a Spanish population. Arch Bronconeumol 2008;44(10):540-545.

27. Andersen I, Camner P, Jensen PL, Philipson K, Proctor DF. A comparison of nasal and tracheobronchial clearance. Arch Environ Health 1974;29(5):290-293.

28. Nakagawa NK, Franchini ML, Driusso P, de Oliveira LR, Saldiva PH, Lorenzi-Filho G. Mucociliary clearance is impaired in acutely ill patients. Chest 2005;128(4):2772-2777.

29. Vanderlei LCM, Silva RA, Pastre CM, Azevedo FM, Godoy MF. Comparison of the Polar S810i monitor and the ECG for the analysis of heart rate variability in the time and frequency domains. Braz J Med Biol Res 2008;41(10):854-859.

30. Gamelin FX, Berthoin S, Bosquet L. Validity of the polar S810 heart rate monitor to measure R-R intervals at rest. Med Sci Sports Exerc 2006;38(5):887-893.

31. Tarvainen MP, Niskanen JP, Lipponen JA, Ranta-aho PO, Karjalainen PA. A software for advanced heart rate variability analysis. 4th European Conference of the International Federation for Medical and Biological Engineering. IFMBE Proc 2009;22:1022-1025.

32. Ribeiro JP, Moraes Filho RS. Heart rate variability as a tool for the investigation of the autonomic nervous system. Rev Bras Hipertens 2005;12(1):14-20

33. Rassi A Jr. Understanding better the analysis measures of heart rate variability. J Diag Cardiol. 8 ed., 2000. http://www.cardios.com.br/ noticias_detalhes.asp?idNoticia $=331 \&$ IdSecao $=24 \&$ IdTipoNoticia $=7$ \&cientifico $=\&$ noticias $=\&$ idmenu $=$ Accessed July 07, 2015.

34. Acharya UR, Joseph PK, Kannathal N, Lim CM, Suri JS. Heart rate variability: a review. Med Biol Eng Comput 2006;44(12):1031-1051.

35. Huikuri HV, Mäkikallio TH, Perkiömäki J. Measurement of heart rate variability by methods based on nonlinear dynamics. J Electrocardiol 2003;36(Suppl):95-99.

36. Task Force of the European Society of Cardiology and the North American Society of Pacing and Electrophysiology. Heart rate variability: standards of measurement, physiological interpretation and clinical use. Circulation 1996;93(5):1043-1065.

37. Yuan R, Hogg JC, Paré PD, Sin DD, Wong JC, Nakano Y, et al. Prediction of the rate of decline in $\mathrm{FEV}_{1}$ in smokers using quantitative computed tomography. Thorax 2009;64(11):944-949.

38. Leung JM, Mayo J, Tan W, Tammemagi CM, Liu G, Peacock S, et al. Plasma pro-surfactant protein $\mathrm{B}$ and lung function decline in smokers. Eur Respir J 2015;45(4):1037-1045.

39. Papathanasiou G, Georgakopoulos D, Georgoudis G, Spyropoulos P, Perrea D, Evangelou A. Effects of chronic smoking on exercise tolerance and on heart rate-systolic blood pressure product in young healthy adults. Eur J Cardiovasc Prev Rehabil 2007;14(5):646-652.

40. Furlanetto KC, Mantoani LC, Bisca G, Morita AA, Zabatiero J, Proença M, et al. Reduction of physical activity in daily life and its determinants in smokers without airflow obstruction. Respirology 2014;19(3):369-375.

41. Van Cauwenberge P, Sys L, De Belder T, Watelet JB. Anatomy and physiology of the nose and the paranasal sinuses. Immunol Allergy Clin North Am 2004;24(1):1-17.

42. Kraemer WJ, Gordon SE, Fragala MS, Bush JA, Szivak TK, Flanagan $\mathrm{SD}$, et al. The effects of exercise training programs on plasma concentrations of proenkephalin peptide F and catecholamines. Peptides 2015;64:74-81.

43. Olséni L, Midgren B, Wollmer P. Mucus clearance at rest and during exercise in patients with bronchial hypersecretion. Scand J Rehabil Med 1992;24(1):61-64.

44. Zhou H, Wang X, Brighton L, Hazucha M, Jaspers I, Carson JL. Increased nasal epithelial ciliary beat frequency associated with lifestyle tobacco smoke exposure. Inhal Toxicol 2009;21(10):875-881.

45. Benowitz NL. Cotinine as a biomarker of environmental tobacco smoke exposure. Epidemiol Rev 1996;18(2):188-204.

46. Kapusta ND, Pietschnig J, Plener PL, Blüml V, Lesch OM, Walter $\mathrm{H}$. Does breath carbon monoxide measure nicotine dependence? J Addict Dis 2010;29(4):493-499.

47. Sandberg A, Sköld CM, Grunewald J, Eklund A, Wheelock ÅM. Assessing recent smoking status by measuring exhaled carbon monoxide levels. PLoS ONE 2011;6(12):e28864

48. Cavaliere F, Volpe C, Gargaruti R, Poscia A, Di Donato M, Grieco G, Moscato U. Effects of acute hypoventilation and hyperventilation on exhaled carbon monoxide measurement in healthy volunteers. BMC Pulm Med 2009;9:51

49. Middlekauff HR, Park J, Moheimani RS. Adverse effects of cigarette and noncigarette smoke exposure on the autonomic nervous system: mechanisms and implications for cardiovascular risk. J Am Coll Cardiol 2014;64(16):1740-1750

50. Alyan O, Kacmaz F, Ozdemir O, Maden O, Topaloglu S, Ozbakir C, et al. Effects of cigarette smoking on heart rate variability and plasma $\mathrm{N}$-terminal pro-B-type natriuretic peptide in healthy subjects: is there the relationship between both markers? Ann Noninvasive Electrocardiol 2008;13(2):137-144

51. Min JY, Paek D, Cho SI, Min KB. Exposure to environmental carbon monoxide may have a greater negative effect on cardiac autonomic function in people with metabolic syndrome. Sci Total Environ 2009;407(17):4807-4811.

52. Kupari M, Virolainen J, Koskinen P, Tikkanen MJ. Short-term heart rate variability and factors modifying the risk of coronary artery disease in a population sample. Am J Cardiol 1993;72(12):897-903

53. Alonso Dde O, Forjaz CL, Rezende LO, Braga AM, Barretto AC, Negrão CE, Rondon MU. Heart rate response and its variability during different phases of maximal graded exercise. Arq Bras Cardiol 1998;71(6):787-792

54. Sala R, Malacarne M, Pagani M, Lucini D. Association between aerobic fitness and indices of autonomic regulation: implications for cardiovascular risk. J Sports Med Phys Fitness 2015 [Epub ahead of print].

55. Karakaya O, Barutcu I, Kaya D, Esen AM, Saglam M, Melek M, et al. Acute effect of cigarette smoking on heart rate variability. Angiology 2007;58(5):620-624

56. Mendonca GV, Pereira FD, Fernhall B. Effects of cigarette smoking on cardiac autonomic function during dynamic exercise. J Sports Sci 2011;29(9):879-886.

57. Katz A, Grosbard A. Does it all go up in smoke? Cigarette smoking and tachyarrhythmias. J Cardiovasc Electrophysiol 2006;17(9):937939

58. Devalia JL, Sapsford RJ, Rusznak C, Toumbis MJ, Davies RJ. The effects of salmeterol and salbutamol on ciliary beat frequency of cultured human bronchial epithelial cells in vitro. Pulm Pharmacol 1992;5(4):257-263

59. Vanderlei LCM, Pastre CM, Hoshi RA, Carvalho TD, Godoy MF. Basic notions of heart rate variability and its clinical applicability. Rev Bras Cir Cardiovasc 2009;24(2):205-217. 